\title{
DOSES DE NITROGÊNIO EM COBERTURA NA CULTURA DO CRAMBE EM CASA DE VEGETAÇÃO
}

\author{
Marita Di Loreto y Sampaio ${ }^{1}$, Renan Ribeiro Barzan ${ }^{1}$, Gustavo Adolfo de Freitas Fregonezi ${ }^{1}$ \\ ${ }^{1}$ Universidade Estadual de Londrina - UEL, Londrina - PR, E-mail: marita_diloreto@hotmail.com, renan_barzan@hotmail.com \\ ${ }^{2}$ Centro Universitário Filadélfia - UNIFIL, Londrina - PR, E-mail: gustavofregonezi@ yahoo.com.br
}

\section{RESUMO}

O objetivo deste trabalho foi avaliar aspectos da produção e nutrição nitrogenada do crambe submetido a doses de nitrogênio $(\mathrm{N})$ em cobertura. Observou-se aumento quadrático na produtividade de grãos e rendimento de óleo, bem como no acúmulo de $\mathrm{N}$ nos grãos, enquanto o teor de óleo foi elevado apenas até as doses mais baixas. Os teores de nitrogênio e proteína dos grãos, contudo, não sofreram influência da adubação nitrogenada de cobertura.

Palavras-chave: Crambe abyssinica, adubação nitrogenada, produtividade, nutrição, biodiesel

\section{TOPDRESSING NITROGEN RATES IN CRAMBE PLANTS GROWN IN GREENHOUSE}

\begin{abstract}
The aim of this study was to evaluate aspects of production and nitrogen nutrition of crambe submitted to rates of topdressing nitrogen $(\mathrm{N})$. It was observed a quadratic increase in the yields of grain and oil, as well as $\mathrm{N}$ accumulation in grains, while oil content increased only until low $\mathrm{N}$ rates. The nitrogen and protein contents of the grains, however, were not influenced by nitrogen fertilization.
\end{abstract}

Keywords: Crambe abyssinica, nitrogen fertilization, yield, nutrition, biodiesel

\section{INTRODUÇÃO}

A crescente preocupação com as consequências ambientais dos combustíveis fósseis e com o suprimento de petróleo mostra a necessidade da pesquisa de biocombustíveis renováveis como alternativa para maior sustentabilidade da cadeia energética (HILL et al., 2006).

O biodiesel apresenta algumas vantagens em relação aos derivados do petróleo, possuindo maior ponto de fulgor, menor liberação de partículas como óxidos de carbono e hidrocarbonetos, é 
biodegradável e possibilita um ciclo fechado do carbono (JASPER et al., 2010).

A produção nacional de biodiesel tem como alicerce as culturas anuais de primavera/verão (JASPER et al., 2010), sendo a soja responsável pela maior parte (SOUZA et al., 2009). Dessa forma, é necessário o estudo de oleaginosas alternativas em que a produção de biodiesel não compete com a de alimentos.

Apesar de ainda não ser muito cultivada no país, a cultura do crambe (Crambe abyssinica Hochst), considerada de inverno, tem grande potencial agrícola e industrial para expansão em regiões de diversas condições ambientais, pela grande rusticidade e tolerância a pragas e doenças, além do elevado teor de óleo (SILVA et al., 2013). Configura-se como uma boa opção para o cultivo na safrinha, com baixo custo de produção e possibilidade de mecanização utilizando os mesmos equipamentos da safra de grãos de verão (PITOL et al., 2010).

Por se tratar de uma planta relativamente nova no âmbito nacional, poucos estudos relacionados à fertilização do crambe são encontrados na literatura, desconhecendo-se sua resposta à adubação (ROSOLEM \& STEINER, 2014). Contudo, sabe-se que o crambe apresenta alta demanda por $\mathrm{N}$, tanto na parte aérea como nos grãos, sendo o nutriente mais extraído e mais exportado pela planta (MAUAD et al. 2013). Colodetti et al. (2013) observaram que o nitrogênio foi $\mathrm{o}$ segundo macronutriente que mais limitou a produção de biomassa por plantas de crambe cultivadas em solução nutritiva sob condições de deficiência, com perdas da ordem de 94,82\% em relação ao controle (solução de Hoagland e Arnon completa).

Como o potencial de resposta do crambe à adubação nitrogenada ainda é pouco conhecido, objetivou-se neste estudo avaliar aspectos produtivos e nutricionais da planta em função de doses de nitrogênio aplicadas em cobertura no cultivo em casa de vegetação.

\section{MATERIAL E MÉTODOS}

O trabalho foi realizado entre os meses de maio e agosto de $2013 \mathrm{em}$ casa de vegetação de vidro, modelo 'capela', no Centro de Ciências Agrárias da Universidade Estadual de Londrina (UEL), Londrina-PR,

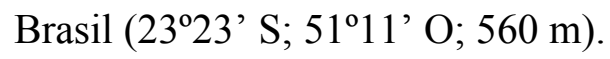

$\mathrm{O}$ delineamento experimental utilizado foi o inteiramente casualizado com cinco tratamentos, representados pelas doses de $0 ; 0,1 ; 0,2 ; 0,4$ e $0,8 \mathrm{~g} \mathrm{~N}$ vaso $^{-1}$, na forma de ureia $(45 \% \mathrm{~N})$, aplicadas em cobertura, realizando-se dez repetições. 
O experimento foi implantado em vasos contendo $5 \mathrm{dm}^{3}$ de um solo coletado no Campus Universitário da UEL, que apresentou as seguintes características químicas, segundo metodologia de Pavan et al. (1992): 0,36 $\mathrm{mg} \mathrm{dm}^{-3}$ de P-Mehlich $1 ; 0,23$ cmol $_{\mathrm{c}} \mathrm{dm}^{-3}$ de $\mathrm{K}^{+} ; 2,9$ cmol $_{\mathrm{c}} \mathrm{dm}^{-3}$ de $\mathrm{Ca}^{2+}$; 0,8 $\mathrm{cmol}_{\mathrm{c}} \mathrm{dm}^{-3}$ de $\mathrm{Mg}^{2+} ; 0,06 \mathrm{cmol}_{\mathrm{c}} \mathrm{dm}^{-3}$ de $\mathrm{Al}^{3+} ; 3,42 \mathrm{cmol}_{\mathrm{c}} \mathrm{dm}^{-3}$ de $\mathrm{H}+\mathrm{Al} ; 7,013 \mathrm{~g} \mathrm{dm}^{-3}$ de $\mathrm{C}$ org.; 12,07 $\mathrm{g} \mathrm{dm}^{-3}$ de Matéria Orgânica e $\mathrm{pH}_{\mathrm{CaCl} 2}$ de 5,3 .

$\mathrm{O}$ solo foi corrigido mediante calagem com 55,50 g vaso $^{-1}$ de Calcário Dolomítico (35\% $\mathrm{CaO}$ e $12 \% \quad \mathrm{MgO})$, seguido da aplicação de 3,67 $\mathrm{g} \mathrm{vaso}^{-1}$ de $\mathrm{P}_{2} \mathrm{O}_{5}$ (Superfosfato Simples, $18 \% \mathrm{P}_{2} \mathrm{O}_{5}$ ) e 4,34 $\mathrm{g} \mathrm{vaso}^{-1}$ de $\mathrm{K}_{2} \mathrm{O}$ (Cloreto de Potássio, $60 \% \mathrm{~K}_{2} \mathrm{O}$ ). Os corretivos e adubos foram devidamente incorporados ao solo anteriormente à semeadura para maior eficiência na reação.

A semeadura do crambe, cultivar FMS Brilhante, foi realizada em 10 de maio de 2013 e a emergência se deu em 17 de maio de 2013, quando foi realizado o raleio, deixando-se três plantas por vaso (unidade experimental). Os vasos foram espaçados em 0,35 m entre linhas, com cinco vasos por metro linear, o equivalente a 42,85 plantas $\mathrm{m}^{-2}$. Os tratos culturais foram realizados de acordo com as recomendações de Colodetti et al. (2012).

O fertilizante nitrogenado (ureia) foi aplicado por ocasião do início do florescimento das plantas, aos 45 dias após a emergência (DAE), no período da manhã devido às menores temperaturas, amenizando a volatilização (CANTARELLA, 2007). Realizou-se ainda uma irrigação subsequente até saturação do solo, verificada pela permanência de água na superfície do solo do vaso, também objetivando menor ocorrência de volatilização ao se incorporar o adubo.

A colheita foi realizada manualmente aos 102 DAE, determinando-se a produtividade de grãos (g vaso $\left.{ }^{-1}, 13 \% \mathrm{U}\right)$, através da trilha manual e pesagem, obtendose a massa total de grãos da parcela (g), corrigida para $13 \%$ de umidade. Os grãos foram então secos em estufa de circulação de ar forçada a $55^{\circ} \mathrm{C}$ até massa constante, moídos em moinho tipo Wiley e submetidos à digestão via úmida para determinação do teor $\left(\mathrm{g} \mathrm{kg}^{-1}\right)$ de nitrogênio $(\mathrm{N})$, pelo método de Kjeldahl, como descrito em Malavolta et al. (1997). Avaliou-se ainda o teor de óleo (\%) no extrato etéreo dos grãos pelo método de Soxhlet com éter de petróleo.

$\mathrm{O}$ rendimento de óleo $\left(\mathrm{g} \mathrm{vaso}^{-1}\right)$ foi obtido conforme Equação 1: 


$$
\begin{array}{r}
\text { Rend. óleo }\left(\text { g vaso }^{-1}\right)= \\
{\left[\frac{\text { Prod. grãos }\left(\text { g vaso }^{-1}\right) \text { x Teor óleo }(\%)}{100}\right]}
\end{array}
$$

O teor de proteína dos grãos $(\%)$ foi obtido conforme Equação 2, utilizando-se o fator de conversão N:proteína de Jones (1931):

Teor proteína $(\%)=\left[\frac{\text { Teor } N\left(\mathrm{~g} \mathrm{~kg}^{-1}\right) \times 6,25}{10}\right]$

(Eq. 2)

$\mathrm{O}$ acúmulo de $\mathrm{N}$ nos grãos $\left(\mathrm{mg} \mathrm{vaso}^{-1}\right.$ ) foi obtido conforme Equação 3:

Acúm. $N$ grãos $\left(m g\right.$ vaso $\left.{ }^{-1}\right)=$

Prod.grãos $\left(\right.$ g vaso $\left.{ }^{-1}, 0 \% U\right) \times$ Teor $N\left(g_{k g}^{-1}\right)$ (Eq. 3)

Os dados foram testados quanto à normalidade e homocedasticidade dos resíduos e submetidos à análise de variância pelo teste $\mathrm{F}$ a $5 \%$ de probabilidade, ajustando-se modelos de regressão em caso de significância $(\mathrm{P}<0,05)$, escolhendo-se aquele de maior $\mathrm{R}^{2}$ e significado biológico, com auxílio do software estatístico SISVAR ${ }^{\circledR}$ (FERREIRA, 2011).

\section{RESULTADOS E DISCUSSÃO}

A produtividade de grãos do crambe foi influenciada pela adubação nitrogenada de cobertura (Tabela 1), apresentando um incremento quadrático em função das doses aplicadas (Figura 1a). Por outro lado, o teor de óleo apresentou um aumento que se ajustou ao modelo $y=b+a x^{0,5}$, com incremento nas doses mais baixas e posterior estabilização (Figura 2a), enquanto o rendimento de óleo aumentou de forma quadrática, seguindo a produtividade de grãos (Figura 1b).

Tabela 1. Resumo da análise de variância para as diferentes variáveis avaliadas em função de doses de nitrogênio aplicadas em cobertura, no florescimento, em casa de vegetação, Londrina - PR, 2013.

\begin{tabular}{ccccc}
\hline Característica & QM tratamentos & F & $\boldsymbol{P}$-valor & C.V.(\%) \\
\hline Produtividade de grãos & 743489,82 & 6,02 & $0,0005^{* *}$ & 42,80 \\
Teor de óleo dos grãos & 50,32 & 2,82 & $0,0360^{*}$ & 18,14 \\
Rendimento de óleo dos grãos & 56753,48 & 4,67 & $0,0031^{* *}$ & 54,23 \\
Teor de proteína dos grãos & 141,51 & 1,81 & $0,1437^{\mathrm{ns}}$ & 37,49 \\
\hline Acúmulo de nitrogênio nos grãos & 589,25 & 8,09 & $0,0001^{* *}$ & 49,65 \\
\hline Teor de nitrogênio dos grãos & 141,51 & 1,81 & $0,1437^{\mathrm{ns}}$ & 37,48 \\
\hline
\end{tabular}

${ }^{\text {ns Não significativo, }}{ }^{* *} \mathrm{e}^{*}$ Significativo a $1 \%$ e $5 \%$ de probabilidade de erro, respectivamente, pelo teste $\mathrm{F}$. 
(a)

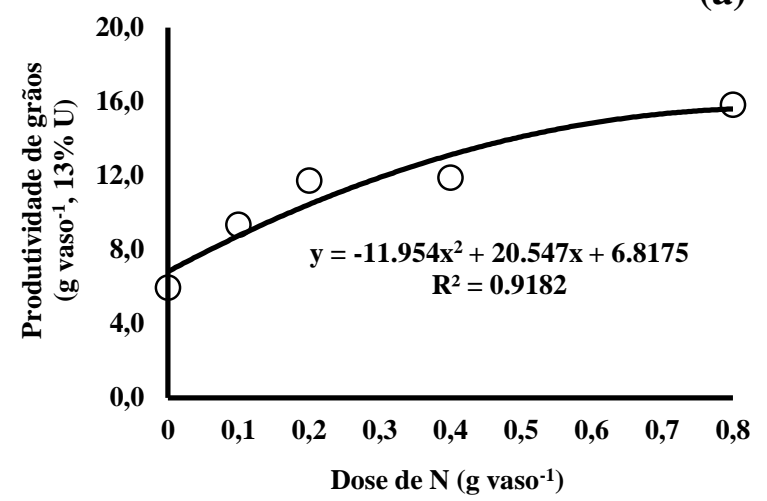

(b)

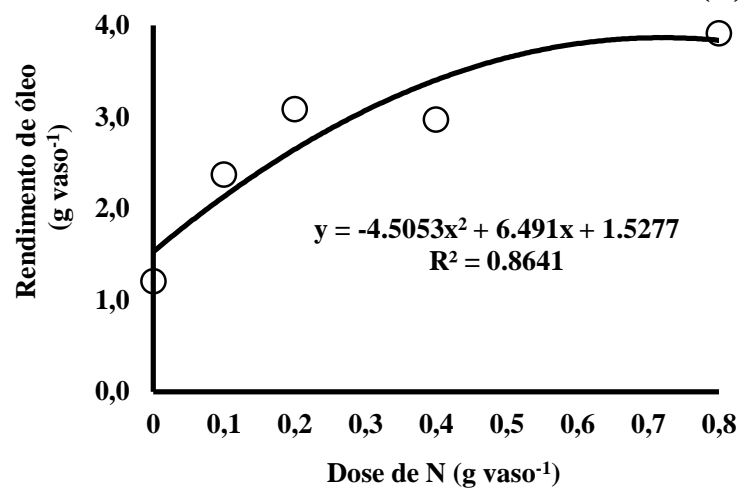

Figura 1. Produtividade de grãos (a) e de óleo (b) em crambe cultivado em casa de vegetação com doses de nitrogênio (N) aplicadas em cobertura, no florescimento, Londrina PR, 2013.
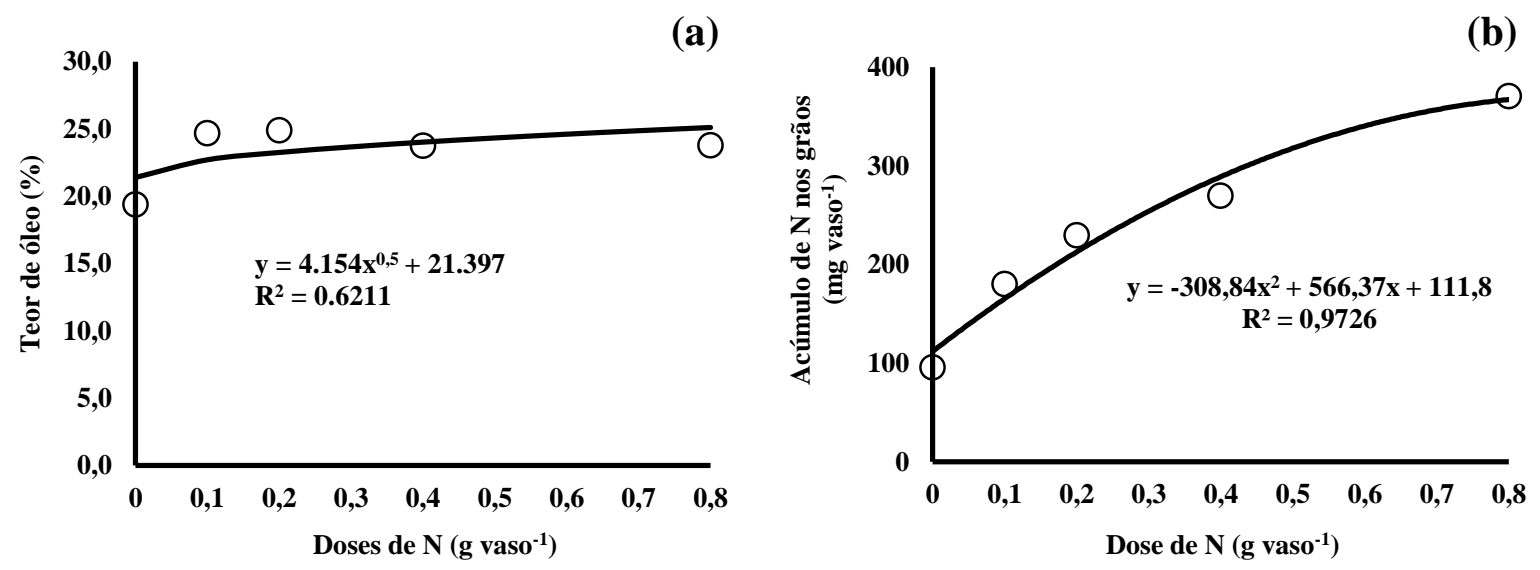

Figura 2. Teor de óleo (a) e acúmulo de nitrogênio (b) nos grãos de crambe cultivado em casa de vegetação com doses de nitrogênio $(\mathrm{N})$ aplicadas em cobertura, no florescimento, Londrina - PR, 2013.

As doses de máxima eficiência técnica ajustadas pelas equações para a produtividade de grãos e rendimento de óleo foram, respectivamente, 0,86 e $0,72 \mathrm{~g} \mathrm{~N}$ vaso $^{-1}$, proporcionando os respectivos valores de $15,65 \mathrm{~g} \mathrm{vaso}^{-1}$ e 3,87 $\mathrm{g} \mathrm{vaso}^{-1}$. Estas doses são próximas à maior dose aplicada $\left(0,8 \mathrm{~g} \mathrm{~N}\right.$ vaso $\left.^{-1}\right)$ e correspondem a 344,0 e $288,0 \mathrm{~kg} \mathrm{~N} \mathrm{ha}^{-1}$.
Vechiatto \& Fernandes (2011) e Ledur et al. (2016) observaram efeito positivo de doses de $\mathrm{N}$ até $120 \mathrm{~kg} \mathrm{ha}^{-1}$ sobre o desenvolvimento de plantas de crambe em características como altura, número de ramos e produção de massa seca, enquanto Alves et al. (2015) observaram influência da adubação nitrogenada também sobre a produtividade de grãos. Dessa forma, constata-se um grande potencial de 
responsividade da cultura do crambe à adubação nitrogenada, inclusive com doses bastante elevadas, como as utilizadas no presente estudo.

Os resultados obtidos neste trabalho a respeito da ausência de efeito sobre o teor de proteína (Tabela 1) e a elevação no teor de óleo dos grãos de crambe (Figura 2a) divergem daqueles comumente reportados na literatura para diferentes culturas oleaginosas. Kaefer et al. (2014), por exemplo, reportaram que o aumento das doses de $\mathrm{N}$ em semeadura elevou o teor de proteína dos grãos e reduziu o teor de óleo na cultura da canola. Em soja, o $\mathrm{N}$ proveniente da inoculação com bactérias simbióticas e sua associação com diferentes fontes de adubo nitrogenado promoveu redução no teor de óleo da cv. Mineira (RUSCHEL et al., 1975). Nobre et al. (2012) relataram efeito linear negativo do $\mathrm{N}$ sobre os teores de óleo em sementes de mamona, ao passo que Carvalho \& Pissaia (2002) não observaram influência da adubação nitrogenada de cobertura sobre o teor de óleo nos aquênios de girassol. Por sua vez, Alves et al. (2015) não obtiveram efeito de doses de $\mathrm{N}$ sobre o teor de óleo em grãos de crambe da mesma cultivar utilizada neste estudo (FMS Brilhante), o que permite constatar que o comportamento aqui observado não se refere a um padrão genético da cultura, mas possivelmente a uma interação entre o fornecimento de $\mathrm{N}$ e outros fatores ambientais particulares da condição em que o trabalho foi desenvolvido.

Os baixos valores de teor de óleo nos grãos obtidos neste trabalho (Figura 2a), em contraste com uma faixa de 36 a $38 \%$ reportada pela Fundação MS (2014), também indicam uma interação entre $\mathrm{O}$ fornecimento de $\mathrm{N}$ e outros fatores ambientais, demonstrando que na condição de ausência de adubação nitrogenada, o N foi fator limitante à produção de óleo e, a partir das doses mais baixas, outros fatores passaram a limitar a obtenção de maiores teores de óleo mesmo com as doses de $\mathrm{N}$ mais elevadas. Com isso, mais estudos devem ser realizados variando-se o fornecimento de $\mathrm{N}$ simultaneamente a outras características, como temperatura, luminosidade e status hídrico, por exemplo, na tentativa de elucidar melhor a dinâmica de síntese e armazenamento de óleo nos grãos.

A ausência de efeito sobre os teores de $\mathrm{N}$ (média geral de 23,6 $\mathrm{g} \mathrm{kg}^{-1}$ ) e, consequentemente, de proteína (média geral de $14,7 \%$ ) dos grãos (Tabela 1), pode ser explicada pelo aumento simultâneo na massa 
de grãos produzida e na alocação do nutriente nesta parte da planta, mantendo assim uma relação entre ambos ( $\mathrm{g} \mathrm{N}$ por $\mathrm{kg}$ de grãos) constante. Isto pode ser constatado pelos comportamentos similares de incremento na produtividade (Figura 1a) e no acúmulo de $\mathrm{N}$ nos grãos (Figura 2b). Apesar do teor constante de $\mathrm{N}$ nos grãos, o aumento no acúmulo do nutriente nesta parte da planta, resultante do aumento na produção de massa em função das doses crescentes, representa uma elevação no potencial de exportação (retirada do nutriente do sistema), o que deve ser considerado no balanço de entradas e saídas do nitrogênio no sistema produtivo.

\section{CONCLUSÕES}

A cultivar de crambe FMS Brilhante se mostra responsiva à aplicação de doses crescentes de nitrogênio em cobertura no florescimento, aumentando de forma quadrática a produtividade de grãos, sendo a dose de máxima eficiência técnica de 0,86 g $\mathrm{N}$ vaso $^{-1}\left(344,0 \mathrm{~kg} \mathrm{ha}^{-1}\right)$, e o rendimento de óleo, com máxima eficiência técnica na dose de $0,72 \mathrm{~g} \mathrm{~N} \operatorname{vaso}^{-1}\left(288,0 \mathrm{~kg} \mathrm{ha}{ }^{-1}\right)$, em condições de casa de vegetação.

O teor de óleo dos grãos é aumentado até doses de $\mathrm{N}$ mais baixas, estabilizando-se com a elevação das mesmas. $O$ teor de nitrogênio e, consequentemente, de proteína dos grãos, não sofre influência das doses aplicadas. $\mathrm{O}$ acúmulo de $\mathrm{N}$ dos grãos, entretanto, é elevado devido ao aumento na produção de massa nesta parte da planta, o que representa maior exportação do nutriente.

\section{REFERÊNCIAS}

ALVES, J.M.; LEANDRO, W.M.; NETO, S.A.S.O.; LEÃO, A.K.M.; ALVES, C.C.F.; SOUCHIE, E.L. 2015. Effect of base saturation and nitrogen dose on cultivation of crambe. African Journal of Agricultural Research, Nairobi, v.10, n. 1, p.14-22.

CANTARELLA, H. 2007. Nitrogênio. In: NOVAIS, R.F.; ALVAREZ V, V.H.; BARROS, N.F.; FONTES, R.L.; CANTARUTTI, R.B.; NEVES, J.C.L. Fertilidade do Solo. Viçosa: SBCS. p.375-470.

CARVALHO, D.B.; PISSAIA, A. 2002. Cobertura nitrogenada em girassol sob plantio direto na palha: I - Rendimento de grãos e seus componentes, índice de colheita e teor de óleo. Scientia Agraria, Curitiba, v.3, n. 1-2, p.41-45.

COLODETTI, T.F.; MARTINS, L.D.; RODRIGUES, W.N.; BRINATE, S.V.B.; TOMAZ, M.A. 2012. Crambe: aspectos gerais da produção agrícola. Enciclopédia Biosfera, Goiânia, v.8, n. 14, p.258-269.

COLODETTI, T.F.; RODRIGUES, W.N.; CHRISTO, L.F.; MARTINS, L.M.; TOMAZ, M.A. 2013. Perda de biomassa causada pela deficiência de macronutrientes em Crambe abyssinica. Enciclopédia Biosfera, Goiânia, v.9, n. 17, p.2027-2038.

FERREIRA, D.F. 2011. Sisvar: a computer statistical analysis system. Ciência e 
Agrotecnologia, Lavras, v.35, n. 6, p.1039-1042.

FUNDAÇÃO MS. 2014. Crambe. Disponível em: http://www.fundacaoms.org.br/produtos/c rambe. Acesso em: 22 Ago. 2014.

HILL, J.; NELSON, E.; TILMAN, D.; POLASKY, S.; TIFFANY, D. 2006. Environmental, economic and energetic costs and benefits of biodiesel and ethanol biofuels. Proceedings of the National Academy of Sciences of the United States of America, Washington, v.103, n. 30, p.11206-11210.

JASPER, S.P.; BIAGGIONI, M.A.M.; SILVA, P.R.A. 2010. Comparação do custo de produção do crambe (Crambe abysssinica Hochst) com outras culturas oleaginosas em sistema de plantio direto. Energia na Agricultura, Botucatu, v.25, n. 4, p.141-153.

JONES, D.B. 1941. Factors for converting percentages of nitrogen in foods and feeds into percentages of protein. Washington, DC: USDA, p.1-22.

KAEFER, J.E.; GUIMARÃES, V.F.; RICHART, A.; TOMM, G.O.; MULLER, A.L. 2014. Produtividade de grãos e componentes de produção da canola de acordo com fontes e doses de nitrogênio. Pesquisa Agropecuária Brasileira, Brasília, v.49, n. 4, p.273280.

LEDUR, E.O.; CHAVES, L.H.G.; FERNANDES, J.D. 2016. Nitrogen and phosphorus on crambe development after off-season corn cultivation. Científica, Jaboticabal, v.44, n. 2, p.263-270.

MALAVOLTA, E.; VITTI, G.C.; OLIVEIRA, S.A. 1997. Avaliação do estado nutricional de plantas: princípios e aplicações. Piracicaba: POTAFOS, 319p.

MAUAD, M.; GARCIA, R.A.; VITORINO, A.C.T.; SILVA, R.M.M.F.; GARBIATE, M.V.; COELHO, L.C.F. 2013. Matéria seca e acúmulo de macronutrientes na parte aérea das plantas de crambe. Ciência Rural, Santa Maria, v.43, n. 5, p.771-778.

NOBRE, R.G.; LIMA, G.S.; GHEYI, H.R.; MEDEIROS, E.P.; SOARES, L.A.A.; ALVES, A.N. 2012. Teor de óleo e produtividade da mamoneira de acordo com a adubação nitrogenada e irrigação com água salina. Pesquisa Agropecuária Brasileira, Brasília, v.47, n. 7, p.991999.

PAVAN, M.A.; BLOCH, M.F.; ZEMPULSKI, H.D.; MIYAZAWA, M.; ZOCOLER, D.C. 1992. Manual de análise química de solo e controle de qualidade. Londrina: IAPAR, 40p.

PITOL, C.; BROCH, D.L.; ROSCOE, R. 2010. Tecnologia de produção: crambe. Maracaju: Fundação MS, 60p.

ROSOLEM, C.A.; STEINER, F. 2014. Adubação potássica para o crambe. Bioscience Journal, Uberlândia, v.30, n. 1, p.140-146.

RUSCHEL, A.P.; SUHET, A.R.; VIANNI, R.; ALMEIDA, D.L. 1975. Efeito de diferentes fontes de nitrogênio e da inoculação na produção de sementes, proteína e óleo em duas cultivares de soja. Pesquisa Agropecuária Brasileira, Brasília, v.10, p.19-23.

SILVA, M.A.P.; BIAGGIONI, M.A.M.; SPEROTTO, F.C.S.; BEZERRA, P.H.S.; BRADÃO, F.J.B. 2013. Qualidade do óleo bruto de grãos de crambe (Crambe abyssinica Hochst) sob diferentes métodos de secagem. Energia na Agricultura, Botucatu, v.28, n. 3, p.193199.

SOUZA, A.D.V.; FÁVARO, S.P.; ÍTAVO, L.C.V.; ROSCOE, R. 2009. Caracterização química de sementes e tortas de pinhão-manso, nabo forrageiro e crambe. Pesquisa Agropecuária Brasileira, Brasília, v.44, n. 10, p.13281335.

VECHIATTO, C.D.; FERNANDES, F.C.S. 2011. Aplicação de nitrogênio em 
cobertura na cultura do crambe.

Cultivando o Saber, Cascavel, v.4, n. 2, p.18-24.

Recebido em: 9/11/2015

Aceito para publicação em: 28/7/2016 